\title{
Novel luminescent materials based on silica doped with an europium(III) complex of 2,6-dihydroxybenzoic acid The crystal structure of $\left[{ }^{n} \mathrm{Bu}_{4} \mathrm{~N}\right]_{2}\left[\mathrm{Eu}(2,6-\mathrm{Hdhb})_{5}\left(\mathrm{H}_{2} \mathrm{O}\right)_{2}\right]$
}

\author{
Paula C.R. Soares-Santos ${ }^{a}$, Helena I.S. Nogueira ${ }^{a}$, Filipe A. Almeida Paz ${ }^{\mathrm{c}}$, \\ Rute A. Sá Ferreira ${ }^{b}$, Luís D. Carlos ${ }^{b}$, Jacek Klinowski ${ }^{c}$, Tito Trindade ${ }^{\mathrm{a}, *}$ \\ ${ }^{a}$ Department of Chemistry, University of Aveiro, CICECO, 3810-193 Aveiro, Portugal \\ ${ }^{\mathrm{b}}$ Department of Physics, University of Aveiro, CICECO, 3810-193 Aveiro, Portugal \\ ${ }^{\mathrm{c}}$ Department of Chemistry, University of Cambridge, Lensfield Road, Cambridge CB2 1EW, UK
}

\begin{abstract}
Novel luminescent materials were prepared by introducing a new Eu ${ }^{3+}$ complex of 2,6-dihydroxybenzoic acid $\left(2,6-\mathrm{H}_{2} \mathrm{dhb}\right)$ into a silica gel made by the sol-gel method. The crystal structure of the resulting complex $\left[{ }^{n} \mathrm{Bu}_{4} \mathrm{~N}\right]_{2}\left[\operatorname{Eu}(2,6-\mathrm{Hdhb})_{5}\left(\mathrm{H}_{2} \mathrm{O}\right)_{2}\right]$ was determined using single-crystal X-ray diffraction. The compound was further characterised using FTIR, FT-Raman and elemental analysis. Photoluminescence measurements were performed for the isolated $\mathrm{Eu}(\mathrm{III})$ 2,6-dihydroxybenzoate complex and also for the related silica composite material. (c) 2003 Elsevier B.V. All rights reserved.
\end{abstract}

Keywords: Chemical synthesis; Europium; Crystal structure and symmetry; Luminescence

\section{Introduction}

Some organic ligands can act as light collectors (antennae) transferring absorbed energy intra-molecularly to lanthanide cations (emitters), yielding highly luminescent lanthanide complexes [1-3]. In this context, we studied the coordination of aromatic ambidentate ligands to lanthanide ions [4]. The photoluminescent behaviour of these complexes incorporated in solid matrices is very interesting. The preparation of silica composites containing luminescent complexes seems a promising strategy, since the resulting materials can be prepared at room temperature by employing the sol-gel method, hence avoiding thermal degradation of the complex [4-8]. The $\mathrm{SiO}_{2}$ matrices also have good mechanical and chemical stability, optical transparency, and are easily prepared using well-known procedures.

The crystal structures of transition-metal complexes of dihydroxybenzoic acids $\left(2,3-\mathrm{H}_{2} \mathrm{dhb}\right.$ or $\left.2,6-\mathrm{H}_{2} \mathrm{dhb}\right)$ can be found in the literature: $\left[\mathrm{NMe}_{4}\right]_{2}\left[\mathrm{MoO}_{2}(2,3-\mathrm{dhb})_{2}\right] \cdot 1.5 \mathrm{H}_{2} \mathrm{O}$ [9], $\left[\mathrm{ReOCl}(2,3-\mathrm{dhb})\left(\mathrm{PPh}_{3}\right)_{2}\right]$ and $\left[\mathrm{ReOCl}(2,6-\mathrm{dhb})\left(\mathrm{PPh}_{3}\right)_{2}\right]$ [10], $\left[\mathrm{Pb}_{2}(2,6-\mathrm{Hdhb})_{4}\right] \cdot 3 \mathrm{H}_{2} \mathrm{O}$ [11], [Cu(2,6-Hdhb $\left.)_{2}\left(\mathrm{H}_{2} \mathrm{O}\right)_{2}\right]$

\footnotetext{
* Corresponding author. Tel.: +351-234-370-726; fax: +351-234-370-084.

E-mail address: ttrindade@dq.ua.pt (T. Trindade).
}

[12] and $\left[\operatorname{Ag}_{2}(2,6-\mathrm{Hdhb})_{2}\right]$ [13] —along with some complexes containing lanthanide cations; $\left[\mathrm{Tb}(2,6-\mathrm{Hdhb})_{3}\right.$ $\left.\left(\mathrm{H}_{2} \mathrm{O}\right)_{4}\right] \cdot 2 \mathrm{H}_{2} \mathrm{O}$ and $\left[\mathrm{Ho}(2,6-\mathrm{Hdhb})_{3}\left(\mathrm{H}_{2} \mathrm{O}\right)_{4}\right] \cdot 2 \mathrm{H}_{2} \mathrm{O}$ [14]. In these complexes, 2,3- $\mathrm{H}_{2} \mathrm{dhb}$ act as a catecholato type chelate, whereas $2,6-\mathrm{H}_{2} \mathrm{dhb}$ shows a more versatile coordination mode (either using both the carboxylate group and an adjacent hydroxyl group in a salicylato type chelate, or the carboxylate group in a monodentate or bidentate fashion).

We have recently reported the preparation and photoluminescence properties of nanocomposites of amorphous silica doped with an europium(III) 3-hydroxypicolinate complex [4]. Here, we report the synthesis of a novel europium complex, $\left[{ }^{n} \mathrm{Bu}_{4} \mathrm{~N}\right]_{2}\left[\mathrm{Eu}(2,6-\mathrm{Hdhb})_{5}\left(\mathrm{H}_{2} \mathrm{O}\right)_{2}\right] \mathbf{I}$, together with its structural characterisation using vibrational spectroscopy, $\mathrm{X}$-ray diffraction and elemental analysis. It is well-known that the luminescent behaviour of lanthanide complexes is very sensitive to the arrangement of atoms within the first coordination sphere [15]. In I, the anionic ligand $2,6-\mathrm{Hdhb}^{-}$is coordinated to the europium cation by the carboxylate groups showing both the monodentate and the bidentate-chelating coordination modes. It was found that $\mathbf{I}$ is easily incorporated into a silica network. A comparative and detailed analysis of the luminescent properties were carried out for both $\mathbf{I}$ and for the related silica composite material $\left(\mathbf{I}-\mathrm{SiO}_{2}\right)$. 


\section{Experimental}

All chemicals were supplied by Aldrich and used without further purification.

\subsection{Preparation of $\left[{ }^{n} \mathrm{Bu} u_{4}\right]_{2}\left[\mathrm{Eu}(2,6-\mathrm{Hdhb})_{5}\left(\mathrm{H}_{2} \mathrm{O}\right)_{2}\right]$}

The europium complex was prepared by the addition of an aqueous solution of the lanthanide salt $\mathrm{Eu}\left(\mathrm{NO}_{3}\right)_{3} \cdot 6 \mathrm{H}_{2} \mathrm{O}$ $(0.856 \mathrm{~g}, 2.00 \mathrm{mmol})$ to an aqueous solution containing 2,6- $\mathrm{H}_{2} \mathrm{dhb}(1.232 \mathrm{~g}, 8.00 \mathrm{mmol})$ and $\mathrm{KOH}(0.448 \mathrm{~g}$, $8.00 \mathrm{mmol}$ ). After stirring the mixture for $1 \mathrm{~h}$ at room temperature, $5 \mathrm{ml}$ of an aqueous solution containing tetrabutylammonium chloride hydrate $\left({ }^{n} \mathrm{Bu}_{4} \mathrm{NCl} \cdot n \mathrm{H}_{2} \mathrm{O}, 1.112 \mathrm{~g}\right.$, $4.00 \mathrm{mmol}$ ) was added and a flocculant white solid was immediately formed. The supernatant solution was decanted and the precipitate collected and washed with distilled water. Crystals of the europium(III) 2,6-dihydroxybenzoate complex suitable for single-crystal X-ray diffraction were obtained after 1 day by slow evaporation of the solvent from the mother solution.

Elemental analysis and spectroscopic data for $\left[{ }^{n} \mathrm{Bu}_{4} \mathrm{~N}\right]_{2}$ [Eu(2,6-Hdhb $\left.)_{5}\left(\mathrm{H}_{2} \mathrm{O}\right)_{2}\right]$-Calculated: C, 55.95\%; $\mathrm{H}$, $1.95 \%$; N, $7.03 \%$; Eu, $10.58 \%$. Found: C, $55.73 \%$; H, $2.02 \% ; \mathrm{N}, 7.14 \% ; \mathrm{Eu}, 10.30 \%$. Selected bands from infrared (solid, $\mathrm{KBr}$ pellet, $v\left(\mathrm{~cm}^{-1}\right)$ )/Raman (solid, $v\left(\mathrm{~cm}^{-1}\right)$, in italics) spectra and tentative assignments: $3475[v(\mathrm{O}-\mathrm{H})]$; 2964/2971 and 2877/2876 [v(C-H)]; 1644/1650 [ $\left.v_{\text {as }}\left(\mathrm{CO}_{2}\right)\right]$; $1294 / 1298\left[v_{\mathrm{s}}\left(\mathrm{CO}_{2}\right)\right] ; 1228 / 1231\left[v_{\mathrm{s}}(\mathrm{C}-\mathrm{O})_{h}\right]$.

\subsection{Preparation of $\mathrm{SiO}_{2}$ nanocomposites}

$\mathrm{The}^{\mathrm{Eu}}{ }^{3+}$ complex was dispersed within a silica matrix using a sol-gel method adapted from Stöber [16]. A mixture of absolute ethanol and DMSO solution (3:1) containing the complex $\left[{ }^{n} \mathrm{Bu}_{4} \mathrm{~N}\right]_{2}\left[\mathrm{Eu}(2,6-\mathrm{Hdhb})_{5}\left(\mathrm{H}_{2} \mathrm{O}\right)_{2}\right](5 \mathrm{mg})$ was added to tetraethoxysilane (TEOS, $0.32 \mathrm{ml}$ ). Alkoxide hydrolysis was promoted by the addition of $2 \mathrm{ml}$ of distilled water to the previous solution. This mixture was allowed to stand over a few days until a rigid gel was formed. The gel was then dried in an oven at $60^{\circ} \mathrm{C}$, leading to solid pieces of a $\left[{ }^{n} \mathrm{Bu}_{4} \mathrm{~N}_{2}\left[\mathrm{Eu}(2,6-\mathrm{Hdhb})_{5}\left(\mathrm{H}_{2} \mathrm{O}\right)_{2}\right] / \mathrm{SiO}_{2}\right.$ composite material $\left(\mathbf{I}-\mathbf{S i O}_{2}\right)$.

\subsection{Instrumentation}

Infrared spectra were measured from $\mathrm{KBr}$ disks using a Mattson 7000 FT instrument. Raman spectra were recorded using a Bruker RFS100/S FT-Raman spectrometer (Nd:YAG laser, $1064 \mathrm{~nm}$ excitation). Elemental analyses for carbon, nitrogen and hydrogen were performed on an Exeter Analytical CE-440 Elemental Analyser (University of Cambridge). The sample was combusted under oxygen at $975{ }^{\circ} \mathrm{C}$ for $1 \mathrm{~min}$, with $\mathrm{He}$ as the purge gas. The lanthanide content in the complexes was measured by ICP (Analytical Laboratories, University of Aveiro). Powder X-ray diffraction patterns (PXRD) were recorded at ambient temperature using a Philips X'Pert instrument, operating with a monochromated $\mathrm{Cu} \mathrm{K} \alpha$ radiation source at $40 \mathrm{kV} / 50 \mathrm{~mA}$. Data were collected using the step counting method (step $0.01^{\circ}, 7 \mathrm{~s}$ per step) in the $2 \leq 2 \theta^{\circ} \leq 60$ range. Theoretical PXRD calculations were performed using the STOE Win XPOW software package [17]. Photoluminescence (PL) spectra were recorded, between $10 \mathrm{~K}$ and room-temperature (RT), using a Jobin Yvon-Spex spectrometer (HR 460) coupled to a R928 Hamamatsu photomultiplier. An Xe arc lamp $(150 \mathrm{~mW})$ coupled to a Jobin Yvon monochromator (TRIAX 180) was used as the excitation source. All the spectra were corrected for the response of the detector. The lifetime measurements were carried out using a pulsed Xe arc lamp $(5 \mathrm{~mJ} /$ pulse, $3 \mu$ s bandwidth) coupled to a Kratos GM-252 monochromator and a Spex 1934C phosphorimeter.

\section{Single-crystal X-ray diffraction}

A suitable single crystal of $\left[{ }^{n} \mathrm{Bu}{ }_{4} \mathrm{~N}_{2}\left[\mathrm{Eu}(2,6-\mathrm{Hdhb})_{5}\right.\right.$ $\left.\left(\mathrm{H}_{2} \mathrm{O}\right)_{2}\right]$ was mounted on a glass fibre using perfluoropolyether oil [18]. Data were collected on a Nonius Kappa CCD diffractrometer with Mo K $\alpha$ graphite-monochromated radiation $(\lambda=0.7107 \AA)$. The structure was solved by direct methods using SHELXS 97 and refined by full-matrix least squares on $F^{2}$ using SHELXL 97 with anisotropic displacement parameters for all non-hydrogen atoms [19,20]. Multi-scan absorption corrections were also applied [21]. Hydrogen atoms from $2,6-\mathrm{Hdhb}^{-}$and $\left[{ }^{n} \mathrm{Bu}_{4} \mathrm{~N}\right]^{+}$were placed in calculated positions, and refined using a riding model with an isotropic displacement parameter fixed at $x$ times $U_{\text {eq }}$ for the atom to which they are bound $(x=1.5$ for all the $\mathrm{O}-\mathrm{H}$ and $-\mathrm{CH}_{3}$ groups, and $x=1.2$ for the remaining hydrogen atoms). Hydrogen atoms from water molecules were located in difference Fourier maps, for which the $\mathrm{O}-\mathrm{H}$ and $\mathrm{H}-\mathrm{O}-\mathrm{H}$ distances were restrained to ensure a chemically reasonable geometry for this molecule. Information concerning crystallographic data collection and structure refinement for $\mathbf{I}$ is summarised in Table 1. Selected bond lengths and angles, and hydrogen-bonding geometry are presented in the caption to Fig. 1.

Crystallographic data (excluding structure factors) for the structure reported in this paper have been deposited with the Cambridge Crystallographic Data Centre as supplementary publication no. CCDC 209241. Copies of the data can be obtained free of charge on application to CCDC, 12 Union Road, Cambridge CB2 2EZ, U.K. (fax: (+44) 1223 336033; e-mail: deposit@ccdc.cam.ac.uk).

\section{Results and discussion}

\subsection{Crystal structure of $\left[{ }^{n} \mathrm{Bu} u_{4}\right]_{2}\left[\mathrm{Eu}(2,6-\mathrm{Hdhb})_{5}\left(\mathrm{H}_{2} \mathrm{O}\right)_{2}\right]$}

Single-crystal X-ray diffraction revealed that the europium(III) 2,6-dihydroxybenzoate complex crystallises 
in the monoclinic and non-centrosymmetric chiral $P 2_{1}$ space group, with the asymmetric unit comprising one anionic Eu-complex plus two tetrabutylammonium cations (Table 1), totally corresponding to an empirical formula of $\left[{ }^{n} \mathrm{Bu}_{4} \mathrm{~N}\right]_{2}\left[\mathrm{Eu}(2,6-\mathrm{Hdhb})_{5}\left(\mathrm{H}_{2} \mathrm{O}\right)_{2}\right]$ I, which was also confirmed using elemental analysis. Phase purity and homogeneity of the bulk were further confirmed using powder $\mathrm{X}$-ray diffraction. The coordination sphere around the $\mathrm{Eu}^{3+}$ centre is composed of five $2,6-\mathrm{Hdhb}^{-}$organic ligands, coordinated by the O-atoms of the carboxylate groups (two forming $\eta^{3}$-syn,syn-chelates and three in a syn-unidentate fashion), and by two solvent molecules, leading to the formation of an $\left[\mathrm{Eu}(2,6-\mathrm{Hdhb})_{5}\left(\mathrm{H}_{2} \mathrm{O}\right)_{2}\right]^{2-}$ anionic complex. The coordination geometry of $\mathrm{Eu}^{3+},\left\{\mathrm{EuO}_{9}\right\}$, can thus be regarded as a distorted tricapped trigonal prism (Fig. 1). Within each 2,6- $\mathrm{Hdhb}^{-}$ligand in the anionic complex, the hydroxyl groups are connected to the carboxylate moieties through very strong $\mathrm{O}-\mathrm{H} . . . \mathrm{O}-$ hydrogen bonds (Fig. 1). Water molecules are also involved in hydrogen bonding, with an interesting feature in the crystal structure being the $\mathrm{O} 2-\mathrm{H} 2 \mathrm{~B} \ldots \mathrm{O} 14^{\mathrm{i}}$ interaction [2.905(4) $\AA$; symmetry code-(i) $x-1, y, z]$ which establishes a bridge between adjacent complex anions and leads to the formation of a one-dimensional hydrogen-bonded anionic polymer running along the $a$ direction of the unit cell.

Table 1

Crystal data and structure refinement information for $\left[{ }^{n} \mathrm{Bu}_{4} \mathrm{~N}\right]_{2}[\mathrm{Eu}(2,6-$ $\left.\mathrm{Hdhb})_{5}\left(\mathrm{H}_{2} \mathrm{O}\right)_{2}\right]$

\begin{tabular}{ll}
\hline & $\mathbf{I}$ \\
\hline Formula & $\mathrm{C}_{67} \mathrm{H}_{101} \mathrm{~N}_{2} \mathrm{O}_{22} \mathrm{Eu}$ \\
Formula weight & 1438.46 \\
Crystal system & Monoclinic \\
Space group & $P 2_{1}$ \\
$a(\AA)$ & $11.078(2)$ \\
$b(\AA)$ & $23.381(5)$ \\
$c(\AA)$ & $14.620(3)$ \\
$\beta\left({ }^{\circ}\right)$ & $109.82(3)$ \\
Volume $\left(\AA^{3}\right)$ & $3562.3(12)$ \\
$Z$ & 2 \\
$D_{\mathrm{c}}\left(\mathrm{g} \mathrm{cm}{ }^{-3}\right)$ & 1.341 \\
$\mu($ Mo K $\alpha)\left(\mathrm{mm}{ }^{-1}\right)$ & 0.954 \\
Crystal size $(\mathrm{mm})$ & $0.20 \times 0.14 \times 0.13$ \\
Crystal type & Colourless blocks \\
$\theta$ range & $3.68-27.47$ \\
Index ranges & $-14 \leq h \leq 13$ \\
& $-30 \leq k \leq 27$ \\
Reflections collected & $-13 \leq l \leq 18$ \\
Independent reflections & 17427 \\
Final $R$ indices $[I>2 \sigma(I)]$ & $12855\left(R_{\text {int }}=0.0269\right)$ \\
& $R 1=0.0363$ \\
Final $R$ indices $($ all data $)$ & $w R 2=0.0829$ \\
Largest diff. Peak and hole & $R 1=0.0465$ \\
\hline
\end{tabular}

\subsection{Spectroscopic characterisation}

IR and Raman selected bands were tentatively assigned, based on those found in the literature for $2,6-\mathrm{H}_{2} \mathrm{dhb}$ transition metal complexes [9]. In the IR spectra of the europium complex and of the ligand, a broad band with a maximum at ca. $3475 \mathrm{~cm}^{-1}$ is assigned to the stretching vibrations of the $\mathrm{O}-\mathrm{H}$ bonds in the phenolic groups and the coordination water molecules (in the case of the complex $)$. The $v(\mathrm{C}=\mathrm{O})$ carboxylate stretch in the free ligand at 1681 and $1674 \mathrm{~cm}^{-1}$ (IR and Raman spectra, respectively), shifts (up to $40 \mathrm{~cm}^{-1}$ ) to a lower wavenumber upon coordination (ca. 1641 and $1650 \mathrm{~cm}^{-1}$, respectively). The symmetric mode $v_{\mathrm{s}}\left(\mathrm{CO}_{2}\right)$ does not show shifts on coordination (at $1294 \mathrm{~cm}^{-1}$ in the complex) when compared to 2,6- $\mathrm{H}_{2} \mathrm{dhb}$ (at $1294 \mathrm{~cm}^{-1}$ ). In the IR spectrum, the band seen at $1236 \mathrm{~cm}^{-1}$ in the free ligand is assigned to the $v(\mathrm{C}-\mathrm{O})_{h}$ phenolic stretch, which shifts ca. $8 \mathrm{~cm}^{-1}$ to lower wavenumbers upon coordination, most probably due to hydrogen bonding.

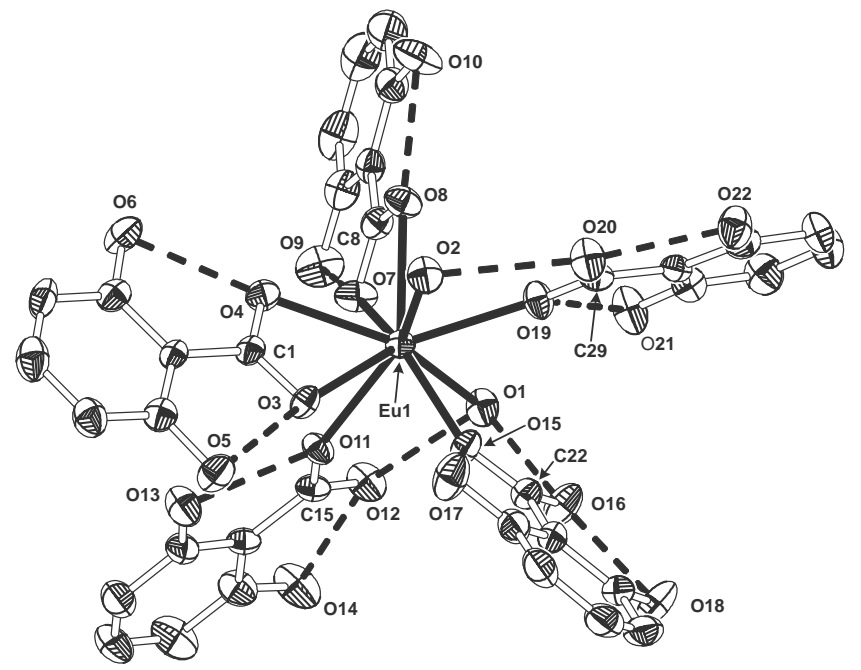

Fig. 1. Schematic representation of the chiral complex anion, $[\mathrm{Eu}(2,6-$ $\left.\mathrm{Hdhb})_{5}\left(\mathrm{H}_{2} \mathrm{O}\right)_{2}\right]^{2-}$, showing the distorted tricapped trigonal prismatic $\left\{\mathrm{LnO}_{9}\right\}$ coordination environment for $\mathrm{Eu}^{3+}$. Thermal displacement ellipsoids are drawn at the $50 \%$ probability level, hydrogen bonds as blackfilled dashed lines and all the hydrogen atoms are omitted for the sake of clarity. Selected bond lengths (in Å): Eu1-O1 2.448(3); Eu1-O2 2.438(3); Eu1-O3 2.519(4); Eu1-O4 2.509(3); Eu1-O7 2.462(3); Eu1-O8 2.537(4); Eu1-O11 2.445(3); Eu1-O15 2.367(3); Eu1-O19 2.421(3). Selected bond angles (in degrees): O1-Eu1-O2 135.60(10); O1-Eu1-O3 131.39(12); O1-Eu1-O7 71.19(12); O1-Eu1-O11 73.29(11); O1-Eu1-O15 77.37(12); O1-Eu1-O19 66.50(11); O2-Eu1-O3 73.05(12); O2-Eu1-O8 81.86(13); O2-Eu1-O11 142.46(11); O2-Eu1-O15 80.03(12); O2-Eu1-O19

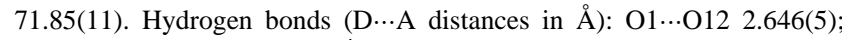

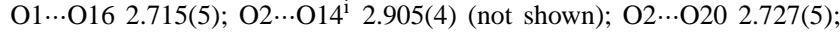

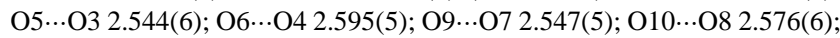

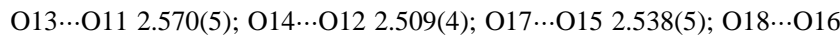

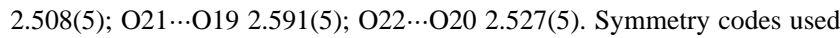
to generate equivalent atoms: (i) $x-1, y, z$. 


\subsection{Photoluminescence}

Fig. 2 illustrates the RT excitation, PLE, spectra monitored around the $\mathrm{Eu}^{3+}$ more intense lines, ${ }^{5} \mathrm{D}_{0} \rightarrow{ }^{7} \mathrm{~F}_{2}$, for $\mathbf{I}$ and $\mathbf{I}-\mathrm{SiO}_{2}$. Both spectra are essentially composed of the intra- $4 \mathrm{f}^{6}{ }^{7} \mathrm{~F}_{0} \rightarrow{ }^{5} \mathrm{H}_{4},{ }^{5} \mathrm{D}_{4},{ }^{5} \mathrm{G}_{J},{ }^{5} \mathrm{~L}_{6},{ }^{5} \mathrm{D}_{3},{ }^{5} \mathrm{D}_{2}$ and ${ }^{5} \mathrm{D}_{1}$ transitions. A large broad band in the lower wavelength side is also detected in the PLE spectrum of $\mathbf{I}-\mathbf{S i O}_{2}$, although with lower intensity with respect to the $\mathrm{Eu}^{3+}$ lines. The appearance of this band only in the PLE spectrum of the composite suggests changes in the local environment of the $\mathrm{Eu}^{3+}$ cations in the two materials.

Fig. 3 shows the RT PL spectra excited at $395 \mathrm{~nm}$ for $\mathbf{I}$ and $\mathbf{I}-\mathbf{S i O}_{2}$. The sharp lines are assigned to transitions between the first $\mathrm{Eu}^{3+}$ excited state, ${ }^{5} \mathrm{D}_{0}$, and the ground septet. Comparing both spectra, marked changes are observed in the number of Stark components and in the respective energy and maximum energy splitting $(\Delta E)$. Moreover, the ${ }^{5} \mathrm{D}_{0} \rightarrow{ }^{7} \mathrm{~F}_{0}$ line, only detectable in the PL spectrum of $\mathbf{I}$ recorded at $10 \mathrm{~K}$, is distinctly showed in the RT PL spectrum of $\mathbf{I}-\mathrm{SiO}_{2}$ and is composed of only one line. The presence of only one ${ }^{5} \mathrm{D}_{0} \rightarrow{ }^{7} \mathrm{~F}_{0}$ line suggests that all the $\mathrm{Eu}^{3+}$ cations lie in the same average local coordination site, since such transition occur between non-degenerated levels. Additionally, the local-field splitting of the ${ }^{5} \mathrm{D}_{0} \rightarrow{ }^{7} \mathrm{~F}_{1}$ and ${ }^{7} \mathrm{~F}_{2}$ transitions is minus discriminated in $\mathbf{I}$ when compared with $\mathbf{I}-\mathrm{SiO}_{2}$. The $\Delta E$ of these transitions is also smaller for $\mathbf{I}$, 98 and $85 \mathrm{~cm}^{-1}$, when compared with that observed for the silica related composite, 200 and $226 \mathrm{~cm}^{-1}$. This indicates that the dispersion of $\mathbf{I}$ within the sol-gel derived silica matrix induced a greater non-homogeneity for the $\mathrm{Eu}^{3+}$-local coordination site. Changing the excitation wavelength between 325 and $395 \mathrm{~nm}$ does not cause any alteration in the $\mathrm{Eu}^{3+} \mathrm{PL}$ lines described above, confirming the suggestion that the $\mathrm{Eu}^{3+}$ ions experience only one local coordination site in both materials. However, for excitation wavelengths smaller than $395 \mathrm{~nm}$, a large broad band between 380 and $700 \mathrm{~nm}$ superimposes the $\mathrm{Eu}^{3+}$ emission for $\mathbf{I}-\mathbf{S i O}_{2}$ (not

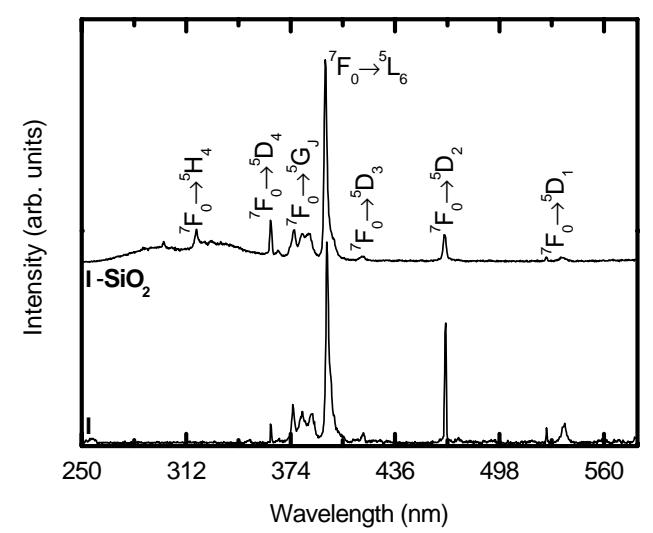

Fig. 2. RT PLE spectra of $\mathbf{I}$ and $\mathbf{I}-\mathbf{S i O}_{2}$, monitored around 615.65 and $612.05 \mathrm{~nm}$, respectively.
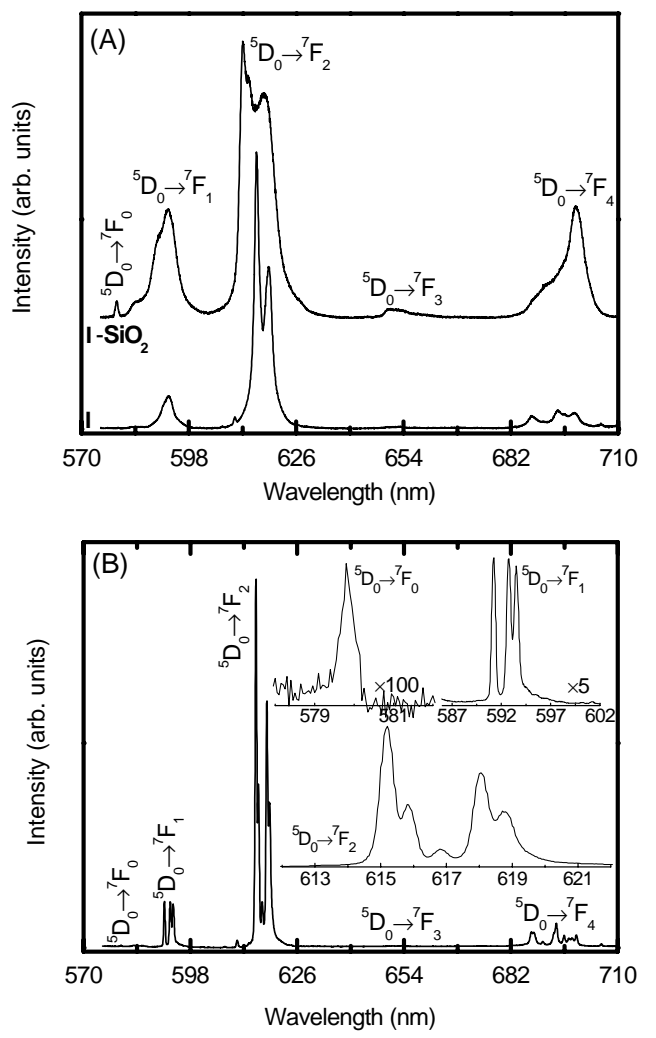

Fig. 3. (A) RT PL spectra of I and $\mathbf{I}-\mathrm{SiO}_{2}$. (B) Low-temperature (10 K) PL spectrum of compound $\mathbf{I}$ at $395 \mathrm{~nm}$ excitation wavelength.

shown). We should note that the presence of this band in the silica-based composite indicates that the ligand-to-metal energy transfer mechanisms are less efficient than those occurring in the $\left[{ }^{n} \mathrm{Bu}_{4} \mathrm{~N}\right]_{2}\left[\mathrm{Eu}(2,6-\mathrm{Hdhb})_{5}\left(\mathrm{H}_{2} \mathrm{O}\right)_{2}\right]$ complex. This band might be related to the emission from the excited states of the ligands [4]. Other evidence supporting differences in the $\mathrm{Eu}^{3+}$ local environment was derived from the ${ }^{5} \mathrm{D}_{0}$ lifetime in the complex and for the related silica based composite. This point is presently under investigation in our laboratory. The ${ }^{5} \mathrm{D}_{0}$ lifetime was measured around the $\mathrm{Eu}^{3+}$ more intense transition and with an excitation wavelength of $395 \mathrm{~nm}$. In both materials the decay profile is well reproduced by a single exponential revealing different lifetime values: $0.325 \pm 0.003$ and $0.253 \pm 0.005 \mathrm{~ms}$, respectively.

\section{Acknowledgements}

We are grateful to the University of Aveiro for a $\mathrm{PhD}$ research grant (PCRSS), and to Fundação Para a Ciência e a Tecnologia (FCT), Portugal, for financial support through the SFRH/BD/3024/2000 (FAAP). We are also grateful for additional financial support from the FCT (grant contract: POCTI/35378/QUI/2000 and POCTI/33653/CTM/2000) supported by FEDER. 


\section{References}

[1] J.M. Lehn, Angew. Chem. Int. Ed. Engl. 29 (1990) 1304.

[2] E.B. Van der Tol, H.J. Van, W. Verhoeven, F.J. Steemers, E.G. Kerver, W. Verboom, D.N. Reinhoudt, Chem. Eur. J. 4 (1998) 2315.

[3] G. Vicentini, L.B. Zinner, J. Zukerman-Schpector, K. Zinner, Coord. Chem. Rev. 196 (2000) 353.

[4] P.C.R. Soares-Santos, H.I.S. Nogueira, V. Félix, M.G.B. Drew, R.A. Sá Ferreira, L.D. Carlos, T. Trindade, Chem. Mater. 15 (2003) 100.

[5] L.R. Matthews, E.T. Knobbe, Chem. Mater. 5 (1993) 1697.

[6] Q. Guodong, W. Minquan, J. Phys. Chem. Solids 58 (1997) 375.

[7] H.H. Li, J. Lin, H.J. Zhang, L.S. Fu, Q.G. Meng, S.B. Wang, Chem. Mater. 14 (2002) 3651.

[8] A.M. Klonkowski, S. Lis, M. Pietraskiewicz, Z. Hnatejko, K. Czarnobaj, M. Elbanowski, Chem. Mater. 15 (2003) 656.

[9] W.P. Griffith, H.I.S. Nogueira, B.C. Parkin, R.N. Sheppard, A.J.P. White, D.J. Williams, J. Chem. Soc. Dalton Trans. (1995) 1775.
[10] G. Bandoli, A. Dolmella, T.I.A. Gerber, J. Perils, J.G.H. Preez, Inorg. Chim. Acta 294 (1999) 114

[11] T. Glowiak, H. Kozlowski, Inorg. Chim. Acta 202 (1992) 43.

[12] F. Cariati, L. Erre, G. Micera, A. Panzanelli, Inorg. Chim. Acta 80 (1983) 57.

[13] G. Smith, C.H.L. Kennard, T.C.W. Mak, Z. Kristallogr. 184 (1988) 275.

[14] T. Glowiak, W. Brzyska, A. Kula, Z. Rzaczynska, M. Jaroniec, J. Coord. Chem. 48 (1999) 477.

[15] F.S. Richardson, Chem. Rev. 82 (1982) 541.

[16] W. Stöber, A. Fink, E.J. Bohn, Colloid Interface Sci. 26 (1968) 62.

[17] STOE, Cie GmbH, Win XPOW THEO Version 1.15 (1999).

[18] T. Kottke, D. Stalke, J. Appl. Crystallogr. 26 (1993) 615.

[19] G.M. Sheldrick, Program for Crystal Structure Solution, SHELXS 97, University of Göttingen, 1997.

[20] G.M. Sheldrick, Program for Crystal Structure Refinement, SHELXL 97, University of Göttingen, 1997.

[21] R.H. Blessing, Acta Crystallogr. A 51 (1995) 33. 